THE INTERNATIONAL

REVIEW OF RESEARCH IN

OPEN AND DISTANCE LEARNING

\title{
Delivery of Open, Distance, and E-Learning in Kenya
}
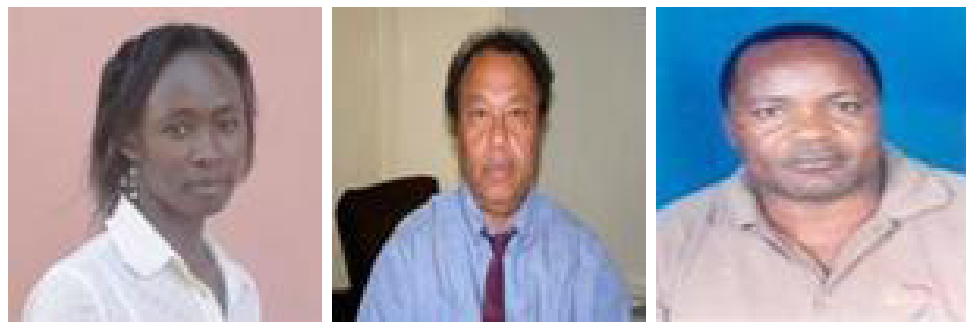

Jackline K. A. Nyerere, Frederick Q. Gravenir, and Godfrey S. Mse Kenyatta University, Kenya

\section{Abstract}

The increased demand and need for continuous learning have led to the introduction of open, distance, and e-learning (ODeL) in Kenya. Provision of this mode of education has, however, been faced with various challenges, among them infrastructural ones. This study was a survey conducted in two public universities offering major components of ODeL, the University of Nairobi and Kenyatta University. These universities were purposely selected for the study, whose respondents included the students registered in ODeL and the lecturers and senior administrators involved. Analysis of the relevant documents was also undertaken, while library literature was reviewed on the integration of ODeL into the provision of education in Kenya. The study established that efficient and optimal delivery of ODeL in Kenya faces both economic and infrastructural challenges. However, strengthening the existing relevant structures would address some of the challenges.

Keywords: Open and distance learning; e-learning; universities 


\section{Background and Literature Review}

The last few decades have witnessed rapid expansion of higher education institutions in Kenya. This can be attributed to increased demand for higher education, partly as a result of increased awareness of the positive benefits of education (Khan, 2001). Education, learning, and acquisition of knowledge and skills have never been of more central importance than they are today. It is becoming increasingly clear that our ability to cope with rapid changes will become the primary measure of success at both macro and micro levels (Khan, 1997). This increased demand has seen ODeL fast becoming an accepted and indispensable part of the mainstream educational platforms in both developed and developing countries, with particular emphasis in the latter (UNESCO, 2002).

Several factors have led to an increasing interest in distance learning. Family commitments, especially among women, is one such factor. Women, especially in the developing countries, must deal with various constraints compared to men in terms of time and resources. The advent of ODeL, however, has widened the opportunities for women and has helped to make education and training more accessible to them as they can now study within their homes. It allows them to study at an individual pace and seek and acquire skills for individual development while, at the same time, fulfilling family responsibilities (Brunner, 1991). We have to recognize that we are living in an age of unprecedented societal change. Technological, cultural, and social upheavals have impacted upon us with regularity, radically changing the way we live, work, and learn (Wheeler, 2000; Edwards, 1997). Accelerating change has often overtaken even the most stable of our social institutions, including education, and the rate of change will no doubt increase in the years ahead. Conflict is another factor. While the risk of war among developed countries will be low, the developing countries will face both internal conflicts and regional interstate wars stemming from religious, ethnic, economic, or political disputes. The number of refugees and homeless or displaced people may increase significantly, necessitating flexible educational provision.

Additionally, there is a growing need for continued skills upgrading and retraining, and technological advances have made it possible to teach more and more subjects at a distance. The new technologies have served to push knowledge acquisition into the domain of the individual. Concomitant with individualization comes the growing autonomy of learners. Technology, and particularly its application in flexible ODeL situations, can be considered vital for increasing and widening access to learning and autonomy for the learner (Laurillard, 1993). The flexibility of open, distance, and e-learning methodologies is the key factor in their emergence as the primary mode for lifelong learning.

\section{ODEL in Africa}

Prior to the emergence of distance learning providers in Africa, many African students obtained various qualifications through ODeL providers in Europe and North America. One of the first distance education universities that emerged in the African continent is the University of South Africa (UNISA), which has been offering correspondence courses since 1946. UNISA's success has spurred the establishment of other ODeL providers in the African continent. Examples of these are the open universities in Nigeria, Tanzania, and Zimbabwe, 
which started out as providers of residential programmes and have now diversified into providing ODeL as well (Juma, 2003).

ODeL techniques are increasingly being employed by a growing number of higher education institutions in Africa. While most of the ongoing distance education initiatives on the continent have been used to upgrade the quality of basic education (Association for the Development of Education in Africa [ADEA], 1999), some countries are taking bold initiatives in implementing Internet-based and satellite-linked distance educational programmes in selected courses. An example is the African Virtual University (AVU), which used to run programmes in Francophone and Anglophone Africa but has since changed its mandate from providing distance learning directly to the learners to providing training to staff in institutions offering ODeL programmes.

\section{Challenges of ODeL in Africa}

For the developing world, and in particular Africa, ODeL is a promising and practical strategy to address the challenge of widening access to, and thus increasing participation in, higher education. It is increasingly being seen as an educational delivery model that is costeffective without sacrificing quality. On the African continent, where resources are scarce and higher education provision is poor, ODeL is viewed as a viable, cost-effective means of expanding provision without costly outlay in infrastructure (Pityana, 2009). As it holds the promise of economies of scale and expanded geographical reach, it is not surprising that many African governments are starting to explore this potential.

While distance education holds promises, a number of obstacles have to be addressed before it can be fully utilized in Africa. There are a number of technological constraints that hinder distance education. Infrastructures outside of major cities remain inadequate. Connectivity beyond major capital cities poses a potential problem in creating a national distance education strategy. Another challenge is the lack of a trained cadre of professionals to support the implementation of distance education. A study conducted in Zimbabwe showed that a majority of the lecturers (97.5\%) facilitating ODeL have no experience in distance education (Mpofu et al., 2012). Effective use of distance learning technologies demands that teaching staff be properly trained in using distance education as a delivery mode. To date, few African scholars are familiar with teaching in an online environment. This situation poses a major challenge in introducing distance education on the continent. A National Education Association (NEA) survey in the United States reported that teaching staff members' top concern about distance education was that they would do more work for the same amount of pay, apparently a merited concern. The NEA (2000) found that most teaching staff members do spend more time on their distance courses than they do on traditional courses, and $84 \%$ of them do not get a reduced workload. Similarly, $63 \%$ of distance teaching staff members receive no extra compensation for their distance courses.

The absence of clearly defined national distance education policies in most African countries poses another challenge. Policies are needed to provide a framework for the development of distance education. With the exception of South Africa, few African countries have clearly defined national policies to guide the development of distance education in their 
respective countries. The absence of such policies is a clear obstacle to the development of distance education. For instance, there are challenges when it comes to learner support services as evidenced by a study carried out in Botswana which revealed that the greatest challenge facing the ODeL tutors was the minimal learner support (Sikwibele \& Mungoo, 2009). This can, however, be resolved through mediation and creation of various ties and connections between the university and the student. The students' main support can be achieved through strong connection with their individual tutors (Macintyre \& Macdonald, 2011). This could also be enhanced through provision of Internet connectivity, which still remains one of the major challenges in Africa, especially in rural areas.

The knowledge gap between the North and South is evident in Sub-Saharan Africa. Here, ODeL has been mainly used to widen access to basic education and to maintain and improve quality in the conventional education system, particularly through in-service training of teachers (UNESCO, 2003). There is a growing attempt by countries in the South to adopt ODeL platforms in order to widen access to education and training. As a Sub-Saharan African country, Kenya has perceived the potential of ODeL. It is thus essential for its educational planning that the opportunities offered by the new mode of learning be realistically examined within the framework of national development plans in general and educational policies in particular.

The first Kenyan Government policy to address ODeL in higher education was the Act of Parliament of 1966, which established the Board of Adult Education. Since independence, however, a number of commissions and reports have highlighted ODeL as an alternative mode of education provision. The latest government initiative, as contained in Sessional Paper No. 1 of 2005 (Republic of Kenya, 2005), recommends the establishment of an open university and the use of ODeL in human resource development at all levels. The practice of ODeL in the country has been at all levels of education and has been provided by different institutions each governed by their own institutional policies (Juma, 2003).

Kenya adopted a National ICT Policy in January 2006. This policy aims at ensuring the availability of accessible, efficient, reliable, and affordable ICT services. The relevant objective in this section on information technology states that government will encourage the use of ICT in schools, colleges, universities, and other educational institutions in the country so as to improve the quality of teaching and learning. According to Farrell (2007), the related strategies are to promote the development of e-learning resources; facilitate public-private partnerships to mobilize resources in order to support e-learning initiatives; promote the development of an integrated e-learning curriculum to support ICT in education; and promote distance education and virtual institutions, particularly in higher education and training, among others. Equally, the Kenya Education Sector Support Program (KESSP), developed in 2005 by the Ministry of Education, prioritizes mainstreaming ICTs into the teaching and learning process.

These efforts notwithstanding, there are a large number of qualified Kenyans who cannot secure places in the existing internal faculties of the national universities. The need for an educated workforce and the opportunity to maximize the use of limited educational re- 
sources, both human and material, call for alternative and innovative methods of learning, which can make university education available beyond lecture halls in Kenya, not limited to a particular time, pace, or space. There is also the need to incorporate ICT in education to improve access to quality education and respond to the challenges of globalization. This study was conducted against this background. It aimed at bringing out the status of and the various challenges that hinder realization of the full potential of ODeL in Kenya.

\section{Specific Objectives}

The specific objectives of the study were to

1. establish access and equity in ODeL delivery in Kenya;

2. establish the adequacy and appropriateness of resources used in ODeL programme delivery; and

3. analyze the challenges of ODeL in Kenya and propose appropriate strategies of overcoming them.

\section{Study Questions}

This study was undertaken to provide information on the following questions:

1. What are the main models of ODeL programme organization and delivery?

2. How equitable is ODeL programme delivery across geographical locations?

3. What is the level of ODeL programme staffing in Kenya?

4. What are the sources of funding for ODeL programmes in Kenya?

5. What are the resources used in ODeL?

6. What are the levels of satisfaction of ODeL participants?

\section{Theoretical Framework}

This study was based on the industrial production model of Otto Peters. This model, which, according to Garrison (2000), was conceived in the mid-1960s, analyzes the structure of distance education and acknowledges the possibility of adopting industrial production techniques such as a division of labor, mass production, and organization to realize economies of scale and reduce unit costs (Peters, 1994). This model is about organizing the educational process to realize economies of scale. The context of this study being a developing country, the resource constraints have hindered adequate provision of higher education to match demand. There is a need, therefore, to look for alternative ways of providing higher education such as ODeL, a mode that is capable of increasing access without necessarily expanding the existing facilities. This mode of delivery thus benefits from the economies of scale.

Peters notes that this model, which has had a considerable influence and to this day domi- 
nates the field of distance education, is ideal because of the structural constraints and the reliance on self-instructional print packages. The model is not, however, a theory of teaching or learning, according to Garrison (2000), but a contribution to clear thought about the organization of distance education. Peters (1994) also describes the industrial approach as "objectification of the teaching process," which reduces the forms of shared learning and keeps learners away from personal interactions and critical discourse.

\section{Methodology}

\section{Study Design}

Descriptive survey was adopted because it is concerned with describing, recording, analyzing, and reporting conditions that exist or existed (Kothari, 1985). The survey would describe the status of ODeL and analyze the challenges of this type of education. Engelhart (1972) further asserts that survey methods are widely used to obtain data useful in evaluating present practices and in providing the basis for decision making.

\section{Sample and Sampling Procedures}

Purposive sampling was used to select two public universities with major components of ODeL, namely the University of Nairobi and Kenyatta University, with the University of Nairobi being the pioneer institution in ODeL. The purposive sampling method was also used to select the study centres used in the study. Six, three from each of the two universities, were selected for the study. The centres included Nairobi, Kisumu, and Garissa for both the University of Nairobi and Kenyatta University. Nairobi was selected to represent the urban setup, Kisumu to represent the rural setup, and Garissa to represent the hardship areas setup. Purposive sampling was also used to select two senior university administrators in ODeL programmes. These are the managers who are directly involved in the provision of ODeL in the two universities. These administrators, the directors of ODeL, one from each of the universities, are more versed with the challenges they face in the delivery of ODeL and are therefore in a position to suggest areas that need improvement.

Randomly, the teaching staff and students enrolled in ODeL were selected to participate in the study. The study sample was arrived at using tables instituted by Krejcie and Morgan (1990). These are tables which help the researcher determine, with 95\% certainty, what the results would have been had the entire population been surveyed.

\section{Research Instruments}

Data was collected through questionnaires for students and lecturers, interview schedules for administrators, and document analysis. A survey was carried out in two universities with major components of ODeL in Kenya, the University of Nairobi and Kenyatta University, to establish the status and challenges of ODeL. Senior university administrators in charge of ODeL, staff, and students participated in the study, which utilized questionnaires for students and staff as well as interviews for senior administrators. 
The students' questionnaire was structured to seek information on their reasons for enrolling in ODeL as opposed to the residential mode of education; whether they are satisfied with the delivery of the programmes; the challenges they face in pursuing the programmes; and their suggestions on ways of improving the programmes.

The questionnaire for the teaching staff was structured to seek information on the training they have had on the delivery of ODeL; the mode of delivery they employ in ODeL; the type of technology they use to reach their distributed students; the challenges they face in provision of the programmes; and their suggestions as to how the programmes could be improved.

Information sought from the directors of ODeL in the two universities included the policy guidelines for ODeL; the facilities employed in ODeL; adequacy of resources for ODeL; the challenges the institutions encounter in provision of the programmes; and what they feel should be done to address the challenges.

Analysis of the relevant documents was also undertaken to capture information on the status of open, distance, and e-learning and the policies guiding this type of education in the two universities under study. Library literature was reviewed on the integration of ODeL into the provision of primary, secondary, and tertiary education in Kenya.

\section{Pretesting of the Instruments}

Before the actual study, pretesting of the instruments was carried out in one of the universities offering ODeL, Strathmore University. Strathmore University was selected because it was the third most developed in provision of ODeL in Kenya after the two participating institutions, the University of Nairobi and Kenyatta University. This was to determine reliability, which is a measure of the degree to which a research instrument yields consistent results or is influenced by random error, which is the deviation from a true measurement (Mugenda \& Mugenda, 1999).

For pretesting purposes, questionnaires were administered to twenty students and ten teaching staff. The open-ended questions were scored by giving a mark for a relevant response and a zero for irrelevant and blank responses. The questions selected were divided into two equal halves for both the students and the teaching staff, dividing the odd against the even numbered items. The scores of the halves were then correlated using the split half measure of reliability. The Pearson product moment correlation coefficient was calculated between the scores obtained for each person on the odd items and the scores obtained on the even items. The student questionnaire yielded a half test coefficient of 0.79 while the teaching staff questionnaire yielded a half test coefficient of 0.81 . The subjects' scores were then corrected using the Spearman-Brown prophecy formula for the full test, and total test coefficients of 0.88 and 0.89 were obtained for the student and teaching staff questionnaires respectively. The instruments were therefore considered reliable since the general rule of thumb in research, a rule that allows one to estimate quickly whenever a large calculation is required, is that reliability should be at least 0.70 (Orodho, 2005). 


\section{Data Collection, Analysis, and Presentation}

Information from university administrators on the developments, available facilities, and challenges in offering ODeL was obtained by directly interviewing them. Information from lecturers and students in ODeL programmes was obtained by administering lecturer and student questionnaires respectively at their centres. After collection, data was coded and the responses from the questionnaires and interview schedules arranged and grouped according to individual research questions. The data from the questionnaires was then entered into appropriate categories in the computer worksheets using the Statistical Package for Social Sciences (SPSS) version 12.0 and Microsoft Excel. Frequencies, percentages, and cross-tabulations were then used to analyze data. Information from the interview schedule was interpreted as per the study objectives.

\section{Results}

\section{Challenges Facing ODeL in Kenya}

In identifying the challenges, the study took into consideration equity in programme delivery across the geographical locations represented in the study, programme staffing, the resources used in the ODeL programmes in Kenya, and the levels of satisfaction of the programme participants.

\section{Equity in Programme Delivery across Geographical Locations}

This was meant to collect information on whether ODeL delivery was consistent and appropriate across all the geographical locations, with Nairobi, Nyanza, and North Eastern Provinces representing the urban, rural, and hardship areas respectively.

The majority of the lecturer respondents felt that the programme delivery was not consistent across all the geographical regions represented in the study. Out of 257 lecturers who participated in the study, only 63 (24.5\%) felt that the ODeL programme delivery was consistent across all the geographical regions, while 194 (75.5\%) felt that there were disparities in the programme delivery across the geographical regions (Table 1).

Table 1

Lecturer Opinion on the Consistency of ODeL Delivery across Geographical Locations

\begin{tabular}{lcc}
\hline Response & $N$ & $\%$ \\
\hline Yes & 63 & 24.5 \\
No & 194 & 75.5 \\
\hline Total & 257 & 100.0 \\
\hline
\end{tabular}


This information was corroborated by the input from students on the services offered in the various regions, especially when it comes to feedback on their exams and assessment tests (Figure 1).

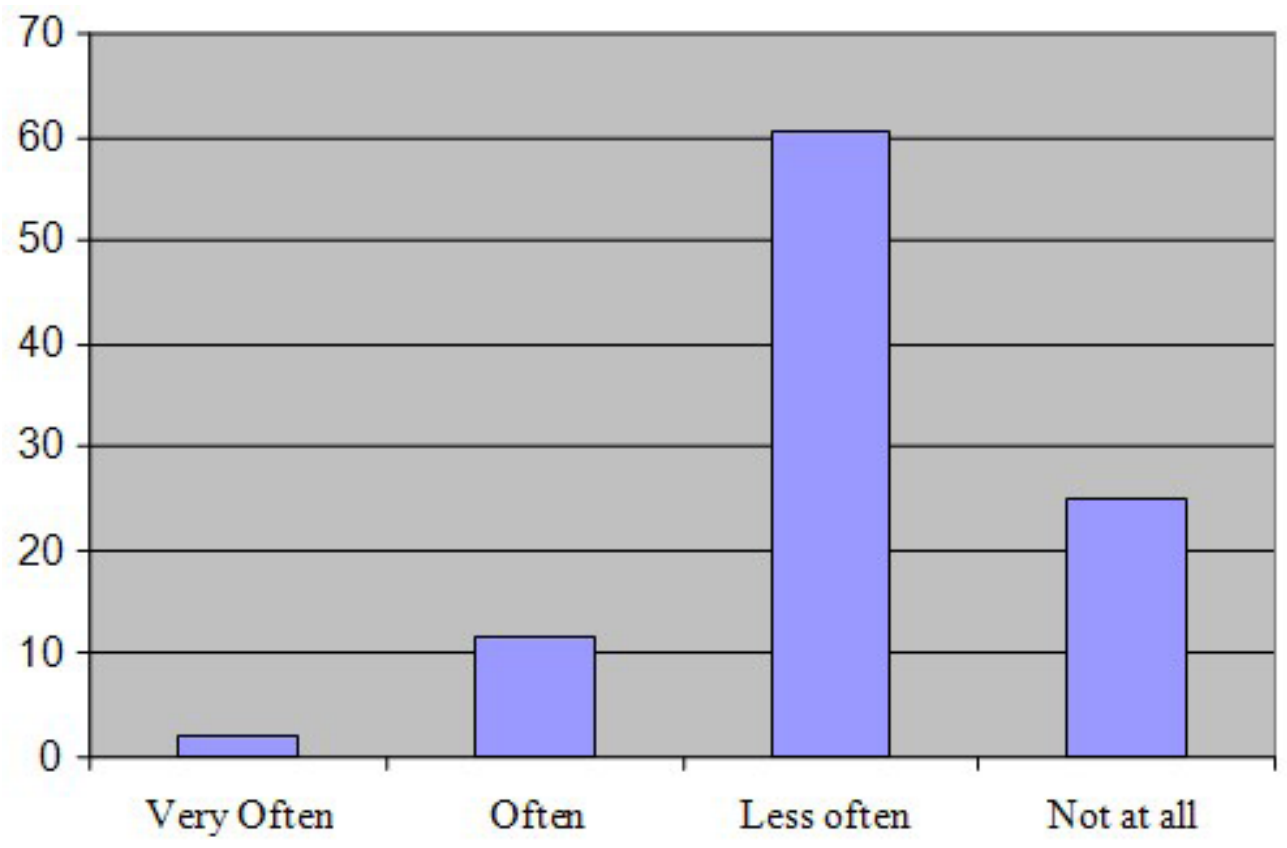

Figure 1. Student opinion on ODeL evaluation feedback.

A large percentage, $60.4 \%$, of the students registered in ODeL in the two universities, received feedback on their end-of-semester examinations, assignments, and continuous assessment tests less often, while $24.8 \%$ did not receive feedback at all. It is also important to note that a greater percentage, $95 \%$, of the students who said that they did not get feedback at all and those who said that they received feedback less often were from North Eastern Province, followed by those from Nyanza Province.

\section{Programme Staffing}

The study sought to establish the levels of staffing and the extent of their training in ODeL delivery techniques. The study found that the ODeL programmes offered by the two institutions relied heavily on staff who facilitated the residential mode programmes. These staff were assisted by staff hired on a part-time basis to facilitate the ODeL programmes, but no staff, especially teaching staff, were employed on a full-time basis to particularly facilitate ODeL programmes in either of the institutions (Table 2). 
Table 2

ODeL Staff Contracts

\begin{tabular}{lcc}
\multicolumn{1}{c}{ Employment Status } & $n$ & $\%$ \\
\hline Full-time & 0 & 0 \\
Part-time & 125 & 48.6 \\
Residential staff & 132 & 51.4 \\
& & \\
Other & 0 & 0 \\
& & \\
\hline Total & 257 & 100.0 \\
\hline \hline
\end{tabular}

Among the lecturers who responded in the study, 125 (49\%) were hired on a part-time basis to facilitate ODeL delivery in the two institutions, and 132 (51\%) were lecturers who facilitate residential mode programmes and were contracted to facilitate the ODeL programme delivery.

The study further sought to establish whether the teaching staff who facilitated these programmes had been given special training on the delivery of ODeL. Few of the lecturer respondents acknowledged having received training on delivery of this mode of education (Figure 2).

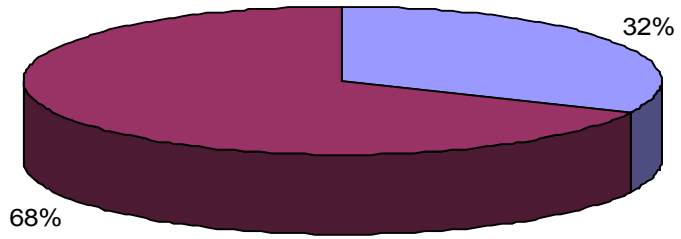

Figure 2. Teaching staff training on ODeL delivery.

Only $32 \%$ of the 257 lecturer respondents had special training in the delivery of ODeL. These lecturers had received training through in-house workshops that were organized mostly by the University of Nairobi, Centre for ODeL, which was actively involved in inhouse training on ODeL material development in Kenya and other East African countries. 


\section{ODeL Programme Resources}

The ODeL programmes in the two universities studied used mainly printed materials for instruction, and supplementary materials such as audio cassettes, video cassettes, slides, and experimental kits which would reinforce each other in achieving the desired goals were generally not in use, primarily due to lack of funds. The institutions lacked study guides that would give a broad view within a context of the courses to be studied.

The University of Nairobi owned resource centres in all the provinces in Kenya, while Kenyatta University owned physical facilities in Nairobi's Ruiru and Parklands Campuses and Mombasa Campus. In the rest of the provinces, the university utilized rented facilities. According to the study findings, most of the students who responded felt that the centres were not effectively utilized (Table 3).

Table 3

Students Response on the Use of Resource Centres

\begin{tabular}{lcc}
\hline Response & $n$ & $\%$ \\
\hline Very effective & 23 & 3.7 \\
Effective & 192 & 30.6 \\
Not effective & 413 & 65.7 \\
\hline Total & 628 & 100.0 \\
\hline
\end{tabular}

Out of 628 student respondents, 215 (34.2\%) felt that the resource centres were used effectively while $413(65.8 \%)$ felt that the centres were not used effectively in providing the student support services.

\section{Satisfaction of Participants in OdeL}

Satisfaction in any service delivery is important, and it acts as an indicator of the quality of service provided. Students who are consumers of the ODeL programmes were asked about their level of satisfaction and motivation. The study revealed that most of the student respondents had very low levels of satisfaction (Figure 3). 


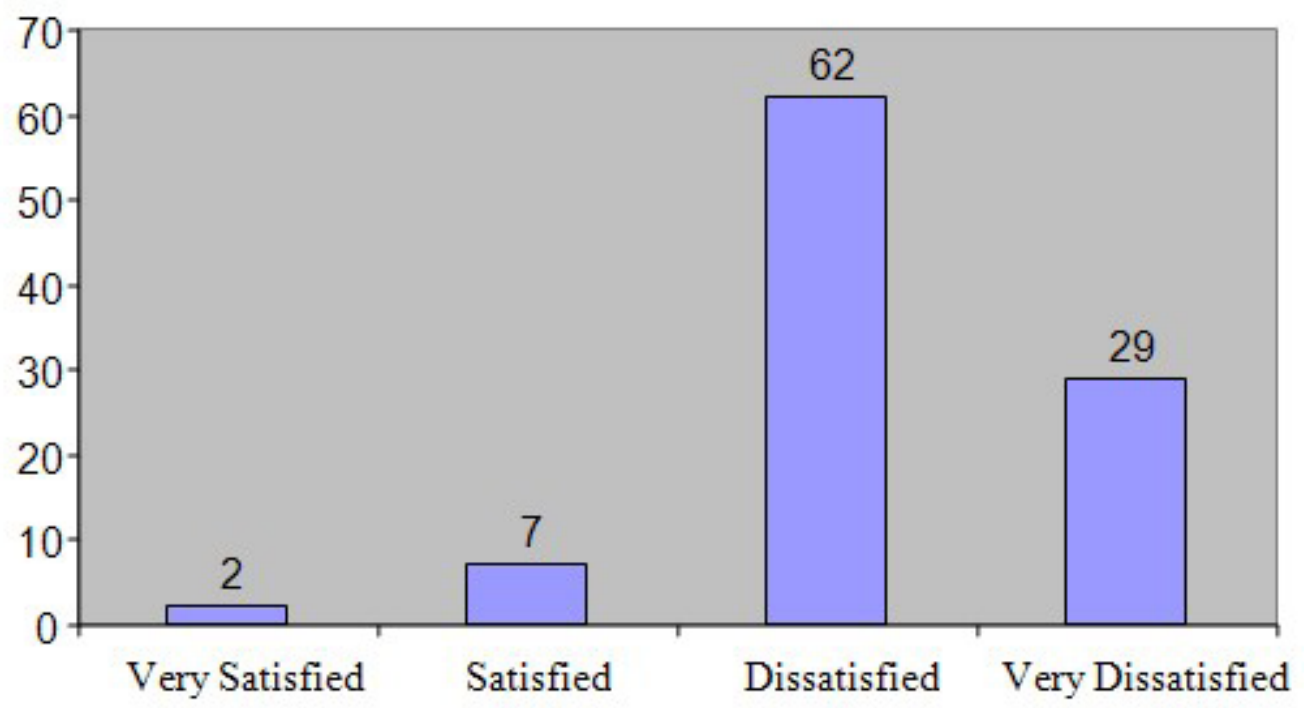

Figure 3. Levels of satisfaction of students in ODeL.

Out of 628 students who participated in the study, 570 (90.8\%) were dissatisfied with the programme organization and delivery, while only about $9 \%$ were satisfied with the programmes delivery and organization.

A closer look at the relationship between the location of students and their levels of satisfaction revealed that 244 (86.1\%) of students from Nairobi, 123 (57.7\%) from Kisumu, and 21 (16.4\%) from Garissa were dissatisfied with the programme delivery, while one (0.4\%) of the student respondents from Nairobi, 71 (33.5\%) from Kisumu, and 182 (83.6\%) from Garissa were very dissatisfied with the programme organization and delivery (Table 4). 
Table 4

Cross-Tabulation of Location of Students and their Levels of Satisfaction

Location

Levels of Satisfaction

Total

\begin{tabular}{cccccc} 
& Very satisfied & Satisfied & Dissatisfied & Very dissatisfied & \\
\hline Nairobi & 11 & 28 & 244 & 1 & 284 \\
& $(3.7 \%)$ & $(9.8 \%)$ & $(86.1 \%)$ & $(.4 \%)$ & $(100.0 \%)$ \\
Kisumu & 0 & 19 & 123 & 71 & 213 \\
& $(.0 \%)$ & $(8.8 \%)$ & $(57.7 \%)$ & $(33.5 \%)$ & $(100.0 \%)$ \\
Garissa & 0 & 0 & 21 & 110 & 131 \\
& $(.0 \%)$ & $(.0 \%)$ & $(16.4 \%)$ & $(83.6 \%)$ & $(100.0 \%)$ \\
\hline Total & 11 & 47 & 388 & 182 & 628 \\
& $(1.8 \%)$ & $(7.5 \%)$ & $(61.8 \%)$ & $(28.9 \%)$ & $(100.0 \%)$
\end{tabular}

There were low levels of motivation among the facilitators of ODeL as well, with only 37 (14.4\%) of the lecturer respondents saying they were motivated in carrying out their duties in ODeL (Figure 4).

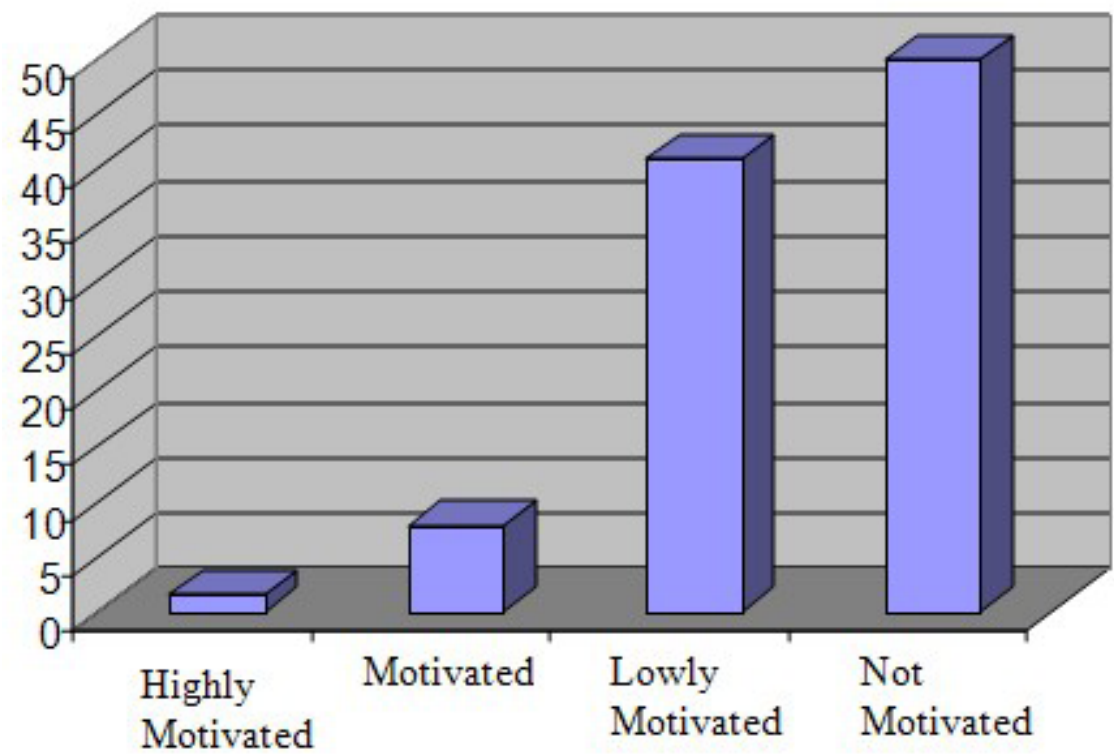

Figure 4. Levels of motivation of lecturers in ODeL. 
As presented in Figure 4, 220 (85.6\%) of lecturers who responded in the study felt that the programme organization and delivery were wanting.

ODeL facilitators were in two employment contract categories, according to the study findings. These were the facilitators hired to offer services on part-time basis and those who were lecturers in internal departments and were seconded by various departmental heads to offer their services to ODeL students. To determine if the staff contracts played any role in their motivation, the study sought to establish the relationship between staff contracts and their levels of motivation (Table 5).

Table 5

Levels of Motivation of Staff in OdeL

\begin{tabular}{cccccc}
\hline $\begin{array}{c}\text { Employment } \\
\text { Status }\end{array}$ & \multicolumn{5}{c}{ Levels of Motivation } \\
& Highly motivated & Motivated & Lowly motivated & Not motivated & Total \\
\hline Part-time & 2 & 11 & 48 & 64 & 125 \\
& $(1.6 \%)$ & $(8.8 \%)$ & $(38.4 \%)$ & $(51.2 \%)$ & $(100.0 \%)$ \\
Residential & 2 & 9 & 57 & 64 & 132 \\
staff & $(1.5 \%)$ & $(6.8 \%)$ & $(43.2 \%)$ & $(48.5 \%)$ & $(100.0 \%)$ \\
\hline Total & 4 & 20 & 105 & 128 & 257 \\
& $(1.6 \%)$ & $(7.8 \%)$ & $(40.9 \%)$ & $(49.8 \%)$ & $(100.0 \%)$ \\
\hline
\end{tabular}

About $2 \%$ of lecturers, both full-time and part-time, were motivated in facilitating the ODeL programmes, while about half the lecturers (48.5\% of residential and $51.2 \%$ of part-time) were not motivated in facilitation of the programmes. The study did not establish any relationship between the facilitators' contracts and their levels of motivation.

\section{Discussion}

\section{Programme Delivery across Geographical Locations}

On programme delivery, the majority of the lecturer respondents felt that there was no consistency across the regions. These lecturers argued that even though the materials used in the delivery of the programme in the locations were the same and were facilitated by the same lecturers, there existed a difference between the attention given to those in the urban centres, who are easier to reach, and those who are far from the urban centers. This was attributed to the fact that the materials, like the modules they mostly relied on, were not 
prepared on time, which necessitated checking regularly with the programme administration to find out when they were ready. This, in essence, means that those in the urban centres, who have no problem with infrastructure like the road and communication network, accessed the materials early enough and had enough time to study before the examinations, which usually took place at the same time in all the regional centres. Students from the other areas, few of whom got timely access to the materials, were left with little time for studying the materials, which put them at a disadvantage. This was also noted by Macintyre and Macdonald (2011), who, in their study carried out in Scotland, recommend that a possible solution could be through mediation and creation of various ties and connections between the university and the student, especially through strong connections between students and their individual tutors.

The other problem cited is in connection with evaluation of the students of ODeL. The lecturer respondents also argued that the continuous assessment tests and the assignments given to the students in the rural and especially the hardship regions took quite a long time to reach the facilitators. This was also attributed to the poor communication and road network. This information was corroborated by the opinions of ODeL students on the evaluation process. These students also indicated that there were disparities, mostly in receiving feedback on their tests and assignments, since most of those who received feedback on assignments more regularly were from the urban centres (Figure 4).

\section{ODeL Programme Staffing}

On staffing, the study established that the ODeL programmes offered by the two institutions that participated in the study rely heavily on staff in the residential mode programmes. The dual-mode approach that makes use of existing academic staff and facilities as in the case of universities in Kenya has been recommended by some studies as it reduces the competition for scarce resources often associated with the establishment of a new institution and erodes staff resistance by offering opportunities for direct participation (Saint, 2000). The study established that most (68\%) of the teaching staff who facilitated these programmes had not been given special training on the delivery of ODeL techniques. These findings are similar to those by Mpofu et al. (2012), where they noted that $97.5 \%$ of the ODeL facilitators in Zimbabwe had not received relevant training. Having well-trained and competent staff is important in providing quality ODeL, yet in the effort to get ODeL programmes into operation in Kenya, insufficient preparation, time, and funding had been given to staff training. Few of the lecturer respondents acknowledged having received training on delivery of this mode of education, which was provided mostly through in-house sessions conducted by the University of Nairobi Centre for ODeL. The majority of these lecturers felt that it would be important for them to receive training on the ODeL delivery techniques.

Given that ODeL is generally based on an indirect teaching relationship, using fundamentally self-teaching methods with the tutor acting as a facilitator to activate the skills and situations needed for self-education, the relatively small percentage of staff trained on ODeL would encourage most of the existing ODeL programmes to adopt patterns of traditional education delivery. 
Additionally, most of the lecturer respondents felt that the number of staff facilitating these programmes was not adequate and that additional staff were required in order to run the programmes effectively. According to the study findings, $90 \%$ of these lecturers felt that the level of staffing was inadequate. This, they said, contributed to overloading and hence lack of adequate attention to the students in the ODeL, a factor that had a bearing on the quality of services offered to the students. The lecturers said that they were heavily burdened with many duties because the majority of them were from internal faculties and were also engaged in teaching the residential programmes.

\section{ODeL Programme Resources}

The universities that participated in the study used mainly print material in delivery of ODeL programmes. Computing resources, both hardware and software, which are crucial in ODeL, are difficult to afford in reasonable quantities and quality. Production of highquality ODeL materials for the country's university programmes appears far more expensive because the cost would include the design of the curriculum and the course authors' fee, remuneration of reviewers and assessors, and the tremendous effort devoted to the presentation of the final product using graphics language and layout style. Staff members were thus forced to use curriculum and study materials meant for the residential model of education, which cannot effectively communicate to learners separated from their tutors. In addition, teaching staff members did not have access to modern libraries. The institutions were faced with a lack of current journals and publications in distance learning and were unable to adequately subscribe to publications due to the limited funds available in universities. The programmes also failed to benefit from economies of scale because of the relatively small numbers $(8,215)$ of students enrolled in the programmes, and yet the fact that many African governments are exploring provision of education through ODeL, according to Pityana (2009), is due to resource constraints. This is because resources are scarce and higher education provision is poor on the African continent, and ODeL is viewed as a viable, cost-effective means of expanding provision without costly outlay in infrastructure.

Technology being very dynamic, universities in Kenya cannot cope with the changes in terms of cost and relevancy (Juma, 2003). Quality ODeL could be achieved through effective application of information technology, and as Hooper and Rieber (1995) note, quality can be enhanced when teachers create environments in which students actively engage in cognitive partnerships with technology. Hooper and Rieber (1995) point out, however, that where technology is not appropriately applied, it is unlikely to improve educational quality and may perpetuate or even exacerbate existing problems instead. The Internet represents a technological breakthrough in ODeL tools, and advances with respect to access and quality of information are essential for making ODeL efficient and effective as an innovation in higher education in Kenya. Adequate Internet connectivity throughout the country has not yet been achieved, and the ODeL programmes in Kenya supplement printed materials largely with audio cassettes.

The resource centres constitute an important base for transmitting content. They are meant to provide facilities for individual and group tutoring and academic guidance and counseling. The ODeL students who responded in the study felt that the centres were not adequately utilized since they had to travel to the head offices to get study materials, which 
were not prepared and dispatched to the centers in time. They also felt that the centers did not do enough to facilitate individual or group tutoring and academic guidance and counseling (Table 4).

\section{Satisfaction of Participants in ODeL}

Satisfaction in delivery of any service is important, and it acts as an indicator of the quality of service provided. Most of the study respondent group, which included the students as consumers of the ODeL programmes and the teaching staff who facilitate ODeL programmes, however, had very low levels of satisfaction. Some of the student respondents felt that their study centres were not adequately utilized in providing them with study materials as they had to travel to the main centres for the materials. They also felt that they did not receive adequate student support services, and they did not receive feedback on their assignments and examinations on time. This agrees with a study in Botswana by Sikwibele and Mungoo (2009), which revealed that the greatest challenge in ODeL was the minimal learner support. Most of the teaching staff respondents attributed their low levels of motivation to inadequate resources, especially the modules used in the programmes. They also felt that the workload was too heavy, given that they were the same lecturers who facilitated the residential mode of education in addition to other responsibilities such as research and publications. The facilitators also raised the issue of compensation, with the majority feeling that it was too low compared to the workload and the time they put into provision of these services. These sentiments by ODeL teaching staff were also established by a survey by NEA (2000).

\section{Conclusion}

The study established that provision of ODeL by Kenyatta University and the University of Nairobi is faced with various challenges that hinder its fully effective implementation. Various challenges touching on nonoptimal utilization of programme facilities, delays in production of study materials, inadequate funding, and low teaching staff levels were identified. Efforts of the ODeL providers in Kenya were also not guided by national policies, posing a challenge in resource mobilization and programme quality issues. These institutions, being dual mode, were overwhelmed and were not able to meet demand for university education. The integration of ICT in education in Kenya, on the other hand, is more recent and on a smaller scale. This is due to resource and infrastructural constraints.

\section{Study Implication}

The major implication of the study is that there is a lot of potential in implementation of ODeL programmes in Kenya which, if fully exploited, could provide the much-needed access to quality education in the country. This could be achieved through, among other things, adequate budgetary and resource provision, proper infrastructure development, training of adequate staff in ODel, and provision of student support services.

For the government, it would be important to develop and articulate national policies on ODeL to facilitate mobilization of resources for ODeL programmes; develop a budgetary 
provision structure for ODeL programmes; and establish proper infrastructure, especially ICT, to support ODeL programmes in the country. Institutions, on the other hand, should, among other things recognize the fact that ODeL is fundamentally different from residential programmes and provide relevant resources; increase the level of trained staff in ODeL delivery techniques; and strengthen the student support services through optimal utilization of the resource centres.

\section{Recommendation for Further Research}

A study should be carried out to investigate why ODeL student support services have not been realized in dual mode institutions. 


\section{References}

Association for the Development of Education in Africa (ADEA). (1999). Tertiary distance learning in Sub-Saharan Africa. ADEA Newsletter, 11(1).

Brunner, C. (1991). Gender and distance learning. Annals of the American Academy of Political and Social Science, 514(1), 133-145.

Edwards, R. (1997). Changing places? Flexibility, lifelong learning and a learning society. London: Routledge.

Engelhart, M. D. (1972). Methods of educational research. Chicago: Rand McNally.

Farrell, G. (2007). ICT in education in Kenya. A survey of ICT and education in Africa: Kenya country report. Retrieved from http://www.infodev.org/en/Publication.409. html

Garrison, R. (2000). Theoretical challenges for distance education in the 21st century: A shift from structural to transactional issues. International Review of Research in Open and Distance Learning, 1(1).

Hooper, S., \& Rieber, L. P. (1995). Teaching with technology. In A. C. Ornstein (Ed.), Teaching: Theory into practice (pp. 154-170). Needham Heights, MA: Allyn and Bacon.

Juma, M. N. (2003). The establishment of a higher education open and distance learning knowledge base for decision makers in Kenya. Nairobi: UNESCO.

Khan, A. W. (1997). Introduction in educational technology 2000: A global vision for open and distance learning. Conference Papers. Vancouver: Commonwealth of Learning.

Khan, A. W. (2001, April). The future of learning - Learning for the future: Shaping the transition. 2oth ICDE World Conference on Open Learning and Distance Education, Düsseldorf, Germany.

Kothari, C. R. (1985). Research methodology: Methods and techniques. New Delhi: Wiley Eastern.

Krejcie, R. V., \& Morgan, D. W. (1990). Determining sample size for research activities. Educational and Psychological Measurement, 30, 609-616.

Laurillard, D. (1993). Rethinking university teaching: A framework for the effective use of educational technology. London: Routledge.

Macintyre, R., \& Macdonald, J. (2011). Remote from what? Perspectives of distance learning students in remote rural areas of Scotland. International Review of Research in Open and Distance Learning, 12(4). 
Mpofu, V., Samukange, T., Kusure, L. M., Zinyandu, T. M., Denhere, C., Huggins, N., Wiseman, C., Ndlovu, S., Chiveya, R., Matavire, M., Mukavhi, L., Gwizangwe, I., Magombe, E., Magomelo, M., \& Sithole, F. (2012). Challenges of virtual and open distance science teacher education in Zimbabwe. International Review of Research in Open and Distance Learning, 13(1).

Mugenda, O., \& Mugenda, A. (1999). Research methods: Qualitative and quantitative approaches. Nairobi: Acts Press.

National Education Association (NEA). (2000). A survey of traditional and distance learning higher education members. Washington, DC: NEA.

Orodho, J. A. (2005). Elements of education and social science research methods. Nairobi: Masola Publishers.

Peters, O. (1994). Distance education and industrial production: A comparative interpretation in outline (1973). In D. Keegan (Ed.), Otto Peters on distance education: The industrialization of teaching and learning (pp. 107-127). London: Routledge.

Pityana, B. (2009). Open and distance learning in the developing world: Trends, progress and challenges. Keynote speech at the 2009 23rd ICDE World Conference, Maastricht, Netherlands.

Republic of Kenya (2005). A policy framework for education, training and research: Meeting the challenges of education, training and research in Kenya in the 21st century. Nairobi: Government Printers.

Saint, W. (2000). Implementation of tertiary distance education: Choices and decisions. World Bank: Knowledge Enterprise, Inc.

Sikwibele, A. L., \& Mungoo, J. K. (2009). Distance learning and teacher education in Botswana: Opportunities and challenges. International Review of Research in Open and Distance Learning, 10(4).

UNESCO (2003). Africa: A survey of distance education 1991. New Papers on Higher Education Studies and Research, No. 4.

UNESCO. (2002). Open and distance learning: Trends, policy and strategy considerations. Retrieved from unesdoc.unesco.org/images/oo12/oo1284/128463e.pdf

Wheeler, S. (2000, May). The traditional university is dead - Long live the distributed university! Keynote Presentation to the European Universities Continuing Education Network Conference, University of Bergen, Norway. 


\section{Athabasca University $\mathbf{I}$}

(c) 